\title{
MONTAGEM DE CÂMARA COM LÂMPADA DE ULTRAVIOLETA DE BAIXO CUSTO
}

Elson Santiago de Alvarenga*, William Argolo Saliba e Benjamin Gonçalves Milagres

Departamento de Química, Universidade Federal de Viçosa, 36570-000 Viçosa - MG

Recebido em 10/8/04; aceito em 31/1/05; publicado na web em 30/6/05

CONSTRUCTION OF A LOW-COST ULTRAVIOLET-VIEWING CABINET WITH LAMP: Thin layer chromatography is a quick, inexpensive and effective way of screening mixtures of non-volatile organic compounds and it is highly recommended for analytical studies. Inspection of plates under ultraviolet light for the detection of colourless compounds should be performed before any further chemical methods are applied. Construction of a low-cost UV-viewing cabinet with lamp employing parts easily found on the local market is described.

Keywords: ultraviolet; chromatography; UV-cabinet.

\section{INTRODUÇÃO}

A cromatografia é provavelmente o método de separação e análise mais utilizado nos laboratórios de química. Cromatografia em camada delgada (CCD) é um método analítico utilizado na identificação de compostos e determinação de sua pureza. O progresso de uma reação química pode ser verificado pela utilização desta técnica. Os adsorventes mais frequientemente utilizados são a sílica gel e a alumina. Após a eluição, a placa deve ser visualizada sob luz ultravioleta antes da revelação química destrutiva da amostra. Como a maioria dos compostos não são modificados pela rápida exposição à radiação ultravioleta, esta técnica é considerada uma análise não destrutiva, podendo a amostra ser recuperada como realizado na cromatografia preparativa ${ }^{1,2}$.

O objetivo deste trabalho foi produzir uma câmara com lâmpada de ultravioleta de baixo custo, utilizando equipamentos adquiridos em casas de materiais elétricos.

\section{PARTE EXPERIMENTAL}

Os equipamentos utilizados na montagem da câmara de ultravioleta são facilmente encontrados em casas de materiais elétricos e são produzidos por diferentes fabricantes. A câmara foi confeccionada em madeira na marcenaria da UFV. O visor de vidro liso e transparente foi adquirido em vidraçaria, sendo posteriormente recoberto por uma película transparente para filtrar as radiações de ultravioleta (INSULFILM UV ${ }^{\mathrm{TM}} 50 \%$ ). A Tabela 1 lista todos os materiais utilizados na montagem do equipamento para a lâmpada de $9 \mathrm{~W}$, juntamente com seu orçamento.

Uma segunda câmara de ultravioleta foi montada utilizando lâmpada germicida de $15 \mathrm{~W}$ e reator de $15 \mathrm{~W}, 127 \mathrm{~V}$. Como a lâmpada de $15 \mathrm{~W}$ é fisicamente maior que a lâmpada de $9 \mathrm{~W}$, a caixa de madeira (dimensões: 24/41/19 cm) foi redimensionada para 24/52/ $19 \mathrm{~cm}$. Todos os outros acessórios foram idênticos para as duas câmaras (lâmpadas de 9 e 15W).

O fundo da câmara (caixa de madeira) é fixo por dois parafusos, sendo removível para fixação e conexão dos equipamentos elétricos.

Os suportes (clipes de metal) para a lâmpada e o reator foram parafusados na parte superior interna da câmara e o starter foi co-

*e-mail: elson@ufv.br
Tabela 1. Lista dos materiais utilizados na confecção da câmara de ultravioleta e seus respectivos preços

\begin{tabular}{lr}
\hline Material & Preço $(\mathrm{R} \$)^{* *}$ \\
\hline Reator, 9W, 127V & 5,50 \\
Lâmpada germicida, $9 \mathrm{~W}, 254 \mathrm{~nm}$, Starlux & 35,00 \\
Starter Fs - 2 com capacitor 110 - 220V, 15 - 20W & 0,90 \\
Soquete para lâmpada & 1,00 \\
Interruptor & 5,00 \\
Câmara: largura: $24 \mathrm{~cm} /$ comprimento: $41 \mathrm{~cm} /$ & \\
altura: 19 cm & $10,00 *$ \\
Visor de vidro: comprimento: $15,4 \mathrm{~cm} /$ largura: $7 \mathrm{~cm}$ & 1,00 \\
Película para bloquear radiações de ultravioleta & \\
(50\% de transparência) & 1,00 \\
Cortina de lona de plástico preta & 1,50 \\
Tomada de dois pinos & 1,10 \\
Fio de cobre & 0,50 \\
Cola superadesiva instantânea & 2,65 \\
Parafusos & 0,45 \\
Fita isolante & 1,40 \\
Valor total & 67,00 \\
\hline
\end{tabular}

*Neste valor não está computada a mão-de-obra; ** em 2004.

lado com cola superadesiva instantânea ("Three Bond"). A cortina de lona de plástico preta foi colada, com a mesma cola, na abertura da câmara para evitar a saída de radiação e manter a câmara escura para facilitar a visualização. $\mathrm{O}$ vidro recoberto com a película transparente foi colocado no encaixe do visor da câmara.

O circuito elétrico foi montado de acordo com a representação esquemática da Figura 1.

\section{RESULTADOS E DISCUSSÃO}

Lâmpadas fluorescentes emitem luz UV após excitação dos átomos de mercúrio que se encontram no estado gasoso, sob baixa pressão, em seu interior. Um revestimento fosforescente na parte interna do tubo da lâmpada absorve a radiação e a transforma em luz visível. As lâmpadas de mercúrio utilizadas em câmaras de UV, espectrômetros e reações fotoquímicas não possuem o revestimento fosforescente pois, nestes casos, são necessárias as radiações de ultravioleta e não as da região do visível. 


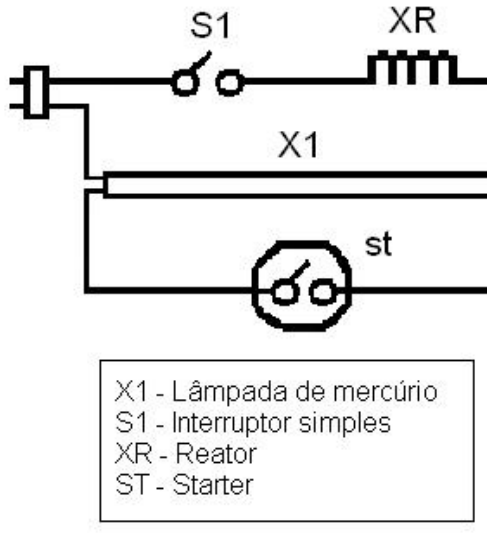

Figura 1. Circuito elétrico da câmara de UV

A posição de compostos coloridos na placa é visualizada sem qualquer dificuldade, desde que sua concentração seja suficientemente alta. Compostos fluorescentes são facilmente localizados através de visualização direta em câmaras de ultravioleta.

A maioria dos adsorventes utilizados em CCD contêm um pó fluorescente que apresenta coloração esverdeada quando irradiado com luz UV. A visualização em câmara de UV de substâncias não fluorescentes em placas contendo indicador $\left(\mathrm{GF}_{254}\right)$ é detectada pelo efeito de extinção ("quench") de fluorescência. Neste caso, a substância é visualizada como uma mancha escura contra um fundo fluorescente esverdeado (indicador). Fluorescência é um fenômeno fotofísico em que a molécula absorve um fóton de alta energia e reemite um fóton de baixa energia (maior comprimento de onda). Normalmente, o fóton absorvido está no ultravioleta e a luz emitida está na região do visível ${ }^{3-5}$.

A radiação ultravioleta é prejudicial à saúde. Assim, é aconselhável trabalhar com óculos de proteção quando estiver exposto à luz ultravioleta. Óculos com lentes de plástico fornecem mais proteção que lentes de vidro. No entanto, óculos comuns promovem apenas proteção parcial, pois a luz pode alcançar os olhos sem atravessar as lentes. Por isso, a nossa preocupação em produzir uma câmara de UV com película para bloquear a radiação no vidro do visor e cortina de lona preta para evitar que a radiação ionizante saia da câmara.

\section{CONCLUSÕES}

As duas câmaras de UV (lâmpadas de 9W e 15W) foram facilmente montadas com a utilização de peças adquiridas no comércio local com preço final (RS\$ 67,00 câmara com lâmpada de 9W) bem inferior ao das câmaras importadas (US\$ 584,50 Spectroline CM UV-viewing cabinet com lâmpada de $6 \mathrm{~W})^{6}$ ou nacionais (R\$ 2500,00 TE-540 Câmara com lâmpada de 4W) 7 . Este equipamento pode ser utilizado tanto em aulas práticas quanto em laboratórios de pesquisas.

\section{REFERÊNCIAS}

1. Collins, C. H.; Introdução a Métodos Cromatográficos, Unicamp: Campinas, 1997.

2. Ewing, G. W.; Métodos Instrumentais de Análise Química, Edgard Blucher: São Paulo, 1972, vol 2.

3. Vogel, A. I.; Vogel's Textbook of Practical Organic Chemistry, $5^{\text {th }}$ ed., rev. Furniss, B. S.; Hannaford, A. J.; Smith, P. W. G.; Tatchell, A. R.; Longman: Londres, 1989, cap 2.

4. Zubrick, J. W.; The Organic Chem Lab Survival Manual: A Student's Guide to Techniques, $4^{\text {th }}$ ed., Wiley: Nova Iorque, 1997, cap. 26-27.

5. Gilbert, A.; Baggott, J.; Essentials of Molecular Photochemistry, Blackwell Scientific Publications: Oxford, 1991, cap 4.

6. Aldrich Catalog Handbook of Fine Chemicals and Laboratory Equipment, 2003-2004; Aldrich Chemical Company, Inc.: São Paulo, Brasil, 2003, p. T149.

7. Catálogo da Tecnal Soluções Precisas para Laboratórios, Tecnal Equipamentos para Laboratório LTDA, Piracicaba, Brasil, 2004, p. 14. 